\title{
Knowledge Sharing in Emerging Economies
}

\author{
Dr M E Burke \\ University of Salford \\ Contact: m.e.burke@salford.ac.uk
}

\begin{abstract}
One of the new factors in Eastern European countries (and there is an acknowledgement that this aspect is inherent in other countries too) is this concept of freely sharing information i.e. the concept of what is known in KM literature of "Knowledge Sharing". Sharing only takes place where there is trust and where there is a shared feeling of ownership of goals. The reasons behind the tendency to share are based on the kind of interpersonal relations between co- workers inherent within the organization and the effects of social relationships within organizational teams. Strengthening the social relationships between individuals in the team is crucial in motivating team members to share knowledge.

New research is currently investigating the concept of "sharing social relationships" and one of the aims of the project is to investigate the barriers to sharing information in a particular type of business - that of the small to medium sized enterprises (the SME) in order to form a comparative study. The results of the study will be used to from a model of "information sharing best practice" for SME who are setting up or using KM systems. The work will examine the barriers to sharing in two newly emerging economies (Poland and Hungary) and one relatively established economy (the UK). At the time of writing the work with Poland and Hungary has been completed and this paper gives the initial results from the Hungarian study.
\end{abstract}

\section{Keywords}

Knowledge Sharing; Knowledge Management, SME, Information Sharing, Emerging Economies; Hungary; Poland

\section{Introduction}

Knowledge Sharing has become a "hot" trend in the last few years. Work such as that by Lin and Chen (2008) on knowledge sharing and the relationship to longer term competitive advantage has never been more relevant or more essential to the continued success of the economy.

Many newly developing countries such as those with poor infrastructure, those in poverty, those emerging from Communist and State rule are moving towards stability by slowly building up businesses such as SME's which are beginning to move towards sharing information both internally within the company and externally to customers, clients and suppliers. Information sharing for many is the first move towards Knowledge 
Sharing and for many businesses these are the stages before a full Knowledge Management system can realistically be addressed.

For many countries the concept of Information Sharing is something which has the potential to be seriously considered with little resource. Many companies are information rich but resource poor and information sharing can be a way to address difficult issues. It can be seen as a way through the mass of data and information in order to impose some kind of structure on the way in which the organisation information flow works.

Knowledge sharing is of increasing importance as one of the building blocks of successful businesses in newly emerging countries. In particular those countries in the former "Eastern bloc" are of increasing importance in the world economy. This is borne out by the increasing number of new and successful SME created in countries that have relatively new "absolute" freedom to access of information. There is a strong need for SME to contribute successfully to that economy and the state of the economy is to some extent, dependent upon business performance and thus businesses compete for what are often, scarce resources.

One critical resource which organizations need is information. Information is required in order to make good quality decisions which assist with the management of the organization and thus can increase overall productivity and profit. Organizations need to adopt and manage Knowledge Management (KM) as a successful KM initiative enables an organization to become "more innovative, better coordinated in its efforts, rapidly commercialize new products, anticipate surprises, become more responsive to market change and reduce the redundancy of the knowledge" (Gold, 2001). However, in order for even the most basic KM system to work effectively, there must be a sense of trust in the organization and this trust is crucial to the open sharing of information.

One of the new factors in Eastern European countries (and there is an acknowledgement that this aspect is inherent in other countries too) is this concept of freely sharing information i.e. the concept of what is known in KM literature of "Knowledge Sharing". Sharing only takes place where there is trust and where there is a shared feeling of ownership of goals. The reasons behind the tendency to share are based on the kind of interpersonal relations between co- workers inherent within the organization and the effects of social relationships within organizational teams. Strengthening the social relationships between individuals in the team is crucial in motivating team members to share knowledge. Within a business, this is often done through a framework of knowledge sharing networks. For example, Dyer and Nobeokai's (2000) work on the Toyota's network can be seen is a purely classical way as having "solved three fundamental dilemmas with regard to knowledge sharing by devising methods to (1) motivate members to participate and openly share valuable knowledge (while preventing undesirable spillovers to competitors), (2) prevent free riders, and (3) reduce the costs associated with finding and accessing different types of valuable knowledge. Toyota has done this by creating a strong network identity with rules for participation and entry into the network. Most importantly, production knowledge is viewed as the property of the network". Yet knowledge sharing in business is also about social relationships and this 
study aims to explore the relationship of knowledge sharing in a business - but from a social viewpoint.

BACS (British Payment Schemes Limited) reported that 37\% of SME's were taking longer than usual for the success of business projects. In addition whilst using social media as a form of advertising would seem to be a low cost high win strategy, research has shown that this is not always the case. "Marketers are prioritising content creation and personalisation in their website investment strategies for the next 12 months and putting social media on the backburner, according to a survey of 250 marketing decision makers, commissioned by EPiServer."

Increasing the amount of information available topped the list of the top three areas of focus (58\%), followed by providing more personalised content (45\%), then developing a member or customer portal (37\%).

As many SME's have static income and rising expenditure there is an increasing need to make SME's more efficient. One way of increasing efficiency is to gain as much advantage as possible with what is already available both internally within the organisation and externally outside the organisation. One commodity which is always available is that of information. In particular information which is translated into knowledge. The effective use of the knowledge - and the way in which it is managed can be critical to the success of an organisation.

This research will add to the understanding of how KM impacts on an SME and the results will be used to create a framework of "best practice" of KM in SME's.

This work is novel in approach as the research takes place in three countries and will provide a comparative study of one relatively stable economy with two newly emerging economies. The countries chosen for the study are Poland, Hungary and the UK. The reasons for choosing Poland and Hungary are that they are emerging economies of former East European bloc countries. The UK has been chosen as an example of an established economy which has examples of good practice. Each country has European Union membership and has an increasing number of new businesses, many of which are initially formed as small and medium sized enterprises (SME). As the European Union aims to become the most dynamic and competitive economic force in the world SME are a particular challenge for the European economy in that they represent one of the keystones of future commercial success and so have the power to greatly enhance the economy. As growth from SME is often the founding for great multinational companies, protecting and enhancing the SME is very much in the interest of the economy of the countries.

This introduction has established the importance of knowledge sharing and formed the context and background to the current "KM and Emerging Economies" project. The next section will give an overview and the project and outline the aims of this paper. One city in each of the countries has been chosen as the primary field site. These are Krakow, Budapest and London. 
The paper deals with two central themes - the different concepts of sharing in societies and the exploration of information sharing in European SME. The paper opens with a discussion of European SME, followed by thoughts about sharing in societies and a consideration of the business relationship between SME and KM. Finally, empirical results are presented from the Hungarian study on SME. The paper concludes with thoughts as to the way forward and considers the future for the sustainable development of information sharing towards robust Knowledge Management systems.

\section{European SME: the sharing relationship.}

However, all organisations also operate within their external environment i.e. society. An analysis of types of society may be helpful as it allows us to consider the aspect of sharing information and the management of knowledge from quite different perspectives. For example, Perrill's (2007) work was concerned with the two concepts of societies which display characteristics associated with individualism and collectism. These types of societies are important and means of charting differences in the concept of sharing (Chen et al 2001; Hofstede and Hofstede, 2005). Yet all the relatively newly "free” Eastern European societies have in common a sense of uncertainty about the future and it is this aspect which we will comment on next.

Uncertainty can be viewed from two areas, that of "relational uncertainty" (according to Berger, 1975) where it is difficult for employees to predict the beliefs and behaviour of colleagues and the that of "informational uncertainty" where the accuracy of the actual information is called into question - as addressed in the information seeking literature (Burke, 2003, 2006, 2007; Choo 2001; Kuhlthau, 1993; Davenport and Prusak; 2000). Both these areas are concerned with fear and trepidation experienced by organisational members about levels of accuracy, quantity of information - if there is sufficient knowledge to make quality decisions and issues about trusting the source of the information.

Three related factors impact on the ability and desire to share information which inevitably affects views and use of knowledge management. These are the type of society in which the organisation operates, the levels of uncertainty prevalent within that society and the types of interpersonal relations in the organisation

\section{Societal Influences}

All organizations also operate within their external environment i.e. society. An analysis of types of society may be helpful as it allows us to consider the aspect of sharing information and the management of knowledge from quite different perspectives. For example, van Der Rijta 's (2007) work was concerned with the two concepts of societies

which display characteristics associated with individualism and collectism. These types 
of societies are important and a means of charting differences in the concept of sharing (Chen et al 1998; Hofstede and Hofstede, 2005). All the relatively new "free" Eastern European societies have in common a sense of uncertainty about the future and this aspect has important consequences regarding the need to share and trust information. Uncertainty can be viewed from two areas, that of "relational uncertainty" (according to Berger, 1975) where it is difficult for employees to predict the beliefs and behaviour of colleagues and the that of "informational uncertainty" where the accuracy of the actual information is called into question - as addressed in the information seeking literature (Burke, 2003, 2006, 2007; Choo 2001; Kuhlthau, 1993; Davenport and Prusak; 2000). Both these areas are concerned with three issues. The first is the fear and trepidation experienced by organizational members about levels of accuracy and quantity of information; the second issue is about both trusting the source of the information and a willingness to trust co workers enough to share information whilst the third issue is about having sufficient relevant knowledge to make quality decisions.

The project builds on these premises and investigates the barriers to one of these major knowledge management processes - that of sharing information.

Sharing generally happens within the context of an information system or a knowledge management system and in order to discuss KM sensibly, we must start with a clear definition. KM can be defined as being about the management of all information in organisations in such a way as to enhance the progress of the organisations aims and objectives. More formally, knowledge management can be defined as "the generation, representation, storage, transfer, transformation, application, embedding and protecting of organisational knowledge" (Schultze and Leidner, 2002). The overall success of the organisation, however, rests on one aspect, that of sharing information.

One of the new factors in Eastern European countries (and there is an acknowledgement that this aspect is inherent in other countries too) is this concept of freely sharing information i.e. the concept of what is known is KM literature of "Knowledge Sharing". Sharing only takes place where there is trust and where there is a shared feeling of ownership of goals. The reasons behind the tendency to share are based on the kind of interpersonal relations between co- workers inherent within the organisation and the effects of social relationships on organisational teams. Strengthening the social relationships between individuals in the team is crucial in motivating team members to share knowledge.

Three related factors impact on the ability and desire to share information which inevitably affects views and use of knowledge management. These are the type of society in which the organisation operates, the levels of uncertainty prevalent within that society and the types of interpersonal relations in the organisation.

\section{European SME and KM: the business relationship}

Considerable work has been published regarding the business relationship between SME and KM (McAdam and Reid, 2001; Sternberg, 1999; Frey S.R. 2002,, Rasheed 2004); the strategy, systems and culture of SME (Bishop and Bouchlaghem, et al., 2008); and the rise of e- business and KM in SME ( Lim and Kloblas, 2000; Koh and Maguire, S). To date only a handful of work has been done on KM and European or International SME (Ataoguz 2005; Dalley, J and Hamilton, 2007, Kailer and Scheff, M, 1999; Nyhan and 
Attwell, 2000.) What is lacking in the literature is a direct comparative study between SME in the former Communist Eastern bloc and SME in the UK, in terms of how they are dealing with knowledge mismanagement processes, in particular the barriers to sharing at the current time.

In the UK SME make up a high percentage of successful business ventures. This is recognized by the government who has over the years put various mechanisms in place in order to assist SME and to ensure that they create and maintain a competitive edge in the UK economy.

As many SME have static income and rising expenditure there is an increasing need to make SME more efficient. One way of increasing efficiency is to gain as much advantage as possible with what is already available both internally within the organization and externally outside the organization. One commodity which is always available is that of information, in particular information which is translated into knowledge. The effective use of the knowledge - and the way in which it is managed can be critical to the success of an organization. The key issues are about sharing information, about having the technology to deliver the information and having the processes in place which will both allow and encourage the free flow of information.

If the KM system fails then the information is not available to make good decisions, the SME will lose its competitive edge, profits will fall and eventually the business will either be merged with a stronger competition or cease to exist.

UK SME has been quite successful and has had the opportunity to develop both information systems and a culture which encourages the sharing of information. However, the success of otherwise of this has not been investigated and this project will allow that investigation to take place.

Hungarian SME has also had help and assistance through government guidance and legislation. For example, it was recently reported by the Hungarian Ministry of Economy and Transport (2007) that "Hungarian small and medium-sized enterprise sector has by now become very similar to SME sectors of less developed old EU member states and newly acceded Countries. Small size enterprises are abundant in the economy and have received help and assistance in the form of grants and a reform of the legal framework." The research carried out on behalf of the Ministry was carried out in all regions of Hungary as SME are considered to be a key way of strengthening the Hungarian economy. By exploring the barriers to sharing information in SME across a sample of sectors it is likely that the work towards a "best practice model" would be relevant to all types of SM thus assisting the Hungarian economy.

SME face a similar situation in Poland as new challenges regarding competitiveness of Polish business sector, posed by the process of accession to the European Union structures, had a significant influence on the quality and culture of doing business in Poland. SME which often strive for survival on the market (mainly due to their low competitiveness) are usually not interested in investments which do not bring immediate effects.

One way of bringing a change which is quickly visible is by paying attention to the information aspects of the business by managing the knowledge as this directly affects both customers and competitors. 
However, the problems faced by SME that are operating in emerging economies are that freedom of access to both information and technology is relatively recent, and there has been a culture of non-sharing and mistrust of information. Around $46 \%$ of SME have no formal KM system due to limited resources and a limited knowledge of implementation of KM and similarly the advantages of using KM. The project will consider one established economy in the UK with two new emerging economies and will add to the understanding of the barriers to sharing information in KM systems and how this impacts on an SME. The results will be used to create a framework of "best practice" of Information Sharing in SME.

One major city in each of the countries was chosen as the primary field site. These are Krakow, Budapest and London.

\section{The exploration of Information Sharing in Hungary: an empirical study.}

\subsection{Hungarian Context}

It was recently reported by the Hungarian Ministry of Economy and Transport.

"The Hungarian small and medium-sized enterprise sector has by now become very similar to SME sectors of less developed old EU member states and newly acceded Countries. Small size enterprises are abundant in the economy. Basic structural figures of SMEs have hardly changed or remained the same over recent years, their businesses are characterised by high labour and low capital intensity. “

Research undertaken internally by the Ministry showed that there were three distinct groups of SME's each with strong identifiable features. The research results were as follows:

"The first group consists of approximately 15 per cent of the enterprises. These are either in the expansive or in the mature phase of their life cycles. They consider their situation good and have an optimistic view of the future. They are typically micro and small enterprises with legal personality, members of groups of companies or entrepreneurial networks. They use and demand up-to-date, specialised sectoralprofessional, technological, business, financial and legal information from both Hungary and abroad.

The second group is made up of nearly 16-20 per cent of enterprises. These are in the start-up or declining phase of their life cycles. They consider their situation bad and have a bleak vision of the future. Personal income of the entrepreneurs is declining. When they need external financial resources, they rely on help from relatives or friends. This group also includes some entrepreneurs not very successful due to social, ethnic or age-related disadvantages. They would also need regular counselling by an advisory, supportive institution with a thorough knowledge of their circumstances and situation. They are potential targets or an education in general business studies, and micro credit. 
The third group includes 65-70 per cent of enterprises, which did not fall into any of the above categories. Their life cycles are varied on a broad range, from start-up to maturity. They consider their situation average and do not expect changes, neither improvements nor decline. More than two thirds are sole proprietors and micro enterprises with single entry Bookkeeping, that is, limited and general partnerships. Their networking level is lower than that of the first group. They mainly produce for the retail market, but the proportion of those selling to other businesses is also significant. They are expanding their staff and some of them are making investments. They are potential participants of business strengthening tenders. They are also the target group of microcredit, of financial institutions operating with mutual guarantee, and of credit associations. Potential customers of banks are among them.”

This work was carried out in all three types of SME that were identified by the report. Offering grant assistance to the different regions of Hungary as SME's are considered to be a key way of strengthening the Hungarian economy.

For the project 35 companies were contacted with 30 actually responding and participating. Semi structured interviews took place, mainly in English as most understood English enough not to require translators. However it should be noted that there are sometimes Hungarian cultural interpretations of English words which affect meaning.

\subsection{Results}

The Hungarian results showed the following factors were ranked as important regarding knowledge sharing - they are divided into barriers, prompters ( what helps push knowledge sharing) and assisters ( what helps to drive knowledge sharing at a broader level).

\section{Barriers}

Government

Organisational hierarchy

Covert Information

Historical culture of secrecy (That information is not available to you)

Fear

Lengthy processes - missed opportunities

\section{Prompters}

Desire to improve at individual level but also collectively

Desire to be better than western counties

Enthusiastic

Improve $n$ no ICT of trainers and providers

Impact of Social media - more immediacy of results 


\begin{abstract}
Assisters
Off the shelf packages available

Family business where younger members were taking on roles (IT familiarity)

Legislation and grants available from government

Push for SME support from government

Increase in tourism/ new industries
\end{abstract}

This is a "snapshot" of the results and is not exhaustive - but gives an example of the nature of the factors identified. Further work and a full set of results will be available and published as they become available. Most Hungarian enterprises were enthusiastic about the concepts of Knowledge Sharing and wanted to find out more about training opportunities. The need to be seen as “young, modern and tech savvy” was important to many respondents. The overall impression was one of enthusiasm and the desire to be seen as enterprising both as individuals but also as a society and a country.

\title{
6. Conclusion
}

This paper aimed to introduce the concept of knowledge sharing and to consider how sharing can assist those countries classed as "emerging economies". This was achieved by outlining a major ongoing comparative study which investigates the concept of information sharing in newly emerging countries with that of an established economy. This paper has explored new perspectives and presents a snapshot the results of the Hungarian country study. Types of societies and aspects of uncertainly both in society and in organizations are briefly discussed. Finally, the work is ongoing in the other countries and it is expected that this project will be extended to other regions and to other countries relatively new to the EU.

The development of sustainable knowledge management in small firms in Europe is critically important to the economy both of the individual country and for the European Union as a whole. The push towards the best competitive economy and the need to be seen as an "entrepreneurial country increased the importance of managing information managing knowledge and sustaining the development of that knowledge.

The question of whether post communist countries will take up the idea of "westernized" Knowledge Management (KM) is open to debate. There are of course alternatives to this and Eastern European countries may well evolve to produce their own particular style of KM. It is interesting to consider the different perspectives which are taken when sharing information is a new factor as new models and frameworks can then be devised to incorporate the changing organizational cultures.

The ongoing research will investigate the barriers to sharing information in SME as a comparative study across three countries. Results will be used to create a model of best practice for "SME Information Sharing in Emerging Economies" which will assist with implementation towards and improving the performance of Knowledge Management in SME. 
Whist the concept of knowledge sharing is inevitably difficult to define. It covers such a wide range of the "newer" disciplines including information sharing; information systems; knowledge management and enterprise and innovation. If relevant business knowledge is shared in an appropriate manner it can lead to major competitive advantage and in turn new developments which will assist the industry and in turn affect the economy of the country. However, what has been obvious so far in this research is the clear energy, passion and commitment to bringing the latest ideas to their enterprise, regions and ultimately their countries.

It is interesting to consider the different perspectives which are taken when sharing information is a new factor. New models and frameworks need to be devised in order to incorporate changed societal and organizational culture. Whether the future for the development of Knowledge Management is sustainable is still to be seen, but from the evidence there is certainly both growth and hope in the area. No doubt the final way forward will depend on two factors - the cooperation of relevant bodies and the appropriate resources being made available. It is hoped that now, today in the freedom of the $21^{\text {st }}$ century both these factors can be given reasonable consideration and a positive response.

(Part of this paper was initially presented as a keynote speech for IIS, Zakopane, Poland 2007and IADIS Portugal)

\section{References}

Ataoguz, C. (2005) Knowledge Management in SMEs: The KM Plus study; University of Fribourg,

Berger, C. R. (1975) Beyond initial interaction: uncertainty, understanding and the development of interpersonal relationships. In H Giles \& R St Clair (Eds) Language and social psychology pp 122-145 Blackwell Oxford

Bishop, J and Bouchlaghem et al., (2008) Ensuring the effectiveness of a knowledge management initiative. Journal of Knowledge Management Vol 12 (4) pp16-29.

Burke, M (2007) Cultural issues, organizational hierarchy and information fulfilment: an exploration of relationships. Library Review Vol. 56 (8) pp 236-245

Burke, M. (2003) Philosophical and theoretical perspectives of organization structures as information processing systems, Journal of Documentation 59 (2) pp131-142

Burke, M. (2006) Achieving Information Fulfilment in the Networked Society. Part 1: Introducing New Concepts New Library World, 107 (9/10).pp. 21-26

Chen C, et. al. (1998) How Can Cooperation Be Fostered? The Cultural Effects of Individualism-Collectivism, Academy of Management Review Vol. 23 (2) pp 285- 304 
Choo, C. et al (2001) Environmental scanning as information seeking and organizational learning. Information Research, Vol7 (1) 2001

World Bank (2006) Country Assistance Strategy Document "prepared for Poland, WB.

Dalley, J. and Hamilton, B.(2001), Knowledge, context and learning in the small business, International Small Business Journal, vol. 18, no. 3,pp. 51-59.

Davenport, T. \& Prusak, L. (2000) Working knowledge: how organisations manage what they know. Boston, Harvard Business School Press

DFID (2003) Report on UK Assistance for Poland's transition 2003-2006. Department for International Development. Series 11.

Dyer, J. H. and Nobeoka, K. (2000), Creating and managing a high-performance knowledge-sharing network: the Toyota case. Strategic Management Journal, 21: 345367

Frey, S., R.,(2002) "Small Business Knowledge Management Success Story", Knowledge and Process Management, vol. 9, no. 3, pp. 172- 177.

Gold, A. Malhortra, A. Segars, A. (2001) Knowledge management: an organizational capabilities perspective. Journal of Information Systems Vol 18 no 1 pp185-214.

Hofstede, G. \& Hofstede G. J, (2005) Cultures and organisations. Software of the mind. London McGraw Hill

Lin and Chen (2008) on Integration and knowledge sharing: transforming to long term competitive advantage. International Journal of Organisational Analysis. Vol 16 (1/2) pp83-108

Kailer, N. and Scheff, M.,(1999) "Knowledge management as a service: cooperation between small and medium-sized enterprises (SMEs) and training, consulting and research institutions”, Journal of European Industrial Training, 23/7, pp.319-328.

Koh, S.C.L. and Maguire, S.,(2004) "Identifying the Adoption of E-Business and Knowledge Management within SMEs”, Journal of Small Business and Enterprise Development, vol.11, no. 3, pp.338-348.

Kulthau, C. (1993) A principle of uncertainty for information seeking. Journal of Documentation Vol. 49 (4) pp39-55 
Lim, D. and Klobas, J.(2000), "Knowledge Management in Small Enterprises”, Electronic Library, vol. 18, no. 6, pp. 420-432. McAdam, R. and Reid, R. (2001) SME and large organization perceptions of knowledge management: comparisons and contrasts. Journal of Knowledge Management.Vol 5 no 3 pp231-241

Nyhan, B.; Attwell, G.; Deitmer, L (2000). Towards the learning region: education and regional innovation in the European Union and the United States. Luxembourg: EUR-OP, (Cedefop reference document, 3006).

Rasheed, M. (2004) The impact of KM on SME. Knowledge Board. Accessed online at http://www.knowledgeboard.com/item/776/23/5/3

Schultze, U. \& Leidner, D, and (2002) Studying KM in IS research: discourses and theoretical assumptions“MIS Quarterly Vol. 26 (3) pp 213-242

Sternberg, R. (1999) Innovative linkages and proximity: empirical results from recent surveys of small and medium sized firms. Journal of regional studies vol 33 no 6 pp 529540

SME web Eserver research on social media. Sept 2010

Van der Rijta, P. (2007) Precious knowledge: virtualness and the willingness to share knowledge in organisational teams. University van Amsterdam. 